Article

\title{
Analysis of the Vacuum Arc Interruption Process in Aviation Intermediate-Frequency Power Supply Systems
}

\author{
Yuan Jiang, Jianwen Wu, Mingxuan Chen * and Wenlei Huo
}

School of Automation Science and Electrical Engineering, Beihang University, Beijing 100191, China; jiangy_luckystar@163.com (Y.J.); wujianwen@buaa.edu.cn (J.W.); ranfengleilei@126.com (W.H.)

* Correspondence: mingxuan_chen@buaa.edu.cn; Tel.: +86-10-8233-8384

Academic Editor: K.T. Chau

Received: 5 January 2017; Accepted: 9 March 2017; Published: 13 March 2017

\begin{abstract}
In this paper, we present our research into the interruption performance of vacuum circuit breakers in aviation intermediate-frequency $(360 \mathrm{~Hz}$ to $800 \mathrm{~Hz})$ power supply systems. Intermediate-frequency vacuum arc experiments were carried out in interrupters with a diameter of $41 \mathrm{~mm}$ and $\mathrm{CuCr} 50$ alloy contact material. The results show that, as the frequency and peak value of the current increase, both the peak value and rise rate of the intermediate-frequency vacuum arc voltage also increase, and the interruption ability decreases. However, compared to the power frequency current at the same value, the erosion of the contacts is weaker over a shorter arc period. When the vacuum arc reignites, metal droplets are emitted from the contacts. The drive force is from the center of the contact to the edge. If the density of the plasmas and metal vapors and the number of the metal droplets reaches a certain level, the arc may break down, which will cause the interruption to fail.
\end{abstract}

Keywords: aviation intermediate-frequency power supply system; vacuum circuit breaker; arc voltage peak value; arc reignition; metal droplet

\section{Introduction}

To reduce the weight and life-cycle cost of more-electric and all-electric aircraft, electro-mechanical actuators (EMAs) and power-by-wire (PBW) technologies are widely used [1,2]. As a result, the capacity of aviation power supply systems has greatly improved. It is because of these advanced technologies that electric power can now be supplied by the variable-frequency generators directly into the engine, as happens in the A380, B787, and C919 aircraft. The line voltage values in these intermediate-frequency systems are AC $200 \mathrm{~V}$ or $400 \mathrm{~V}$, and the current frequency range is $360-800 \mathrm{~Hz}$. Compared to a $50 / 60 \mathrm{~Hz}$ power supply, the current rate $\mathrm{d} i / \mathrm{d} t$ at the zero moment increases, the rise rate of the recovery voltage $\mathrm{d} u / \mathrm{d} t$ becomes faster, and the eddy current effect is more apparent with the increase in the current frequency. The arc breaking process tends to be very difficult due to the growth of the current value in the case of a short circuit error, in which case the instantaneous current peak value can reach $20 \mathrm{kA}$ or more. Consequently, it is necessary to use a circuit breaker with large current breaking capability and high reliability to ensure that the interruption is successful in the aviation intermediate-frequency power system. Vacuum circuit breakers have been widely used in medium voltage power distribution systems, and are physically small, light-weight, and provide large current breaking capability and high reliability, all of which are important strengths in applications in the field of aviation.

In terms of investigations into intermediate-frequency vacuum arcs, Wang [3,4] investigated the microscopic parameters, behaviors, and characteristics of intermediate-frequency vacuum arcs in axial magnetic field (AMF) contacts. Zhu [5-7] studied the arc movement, arc mode, and dynamic 
voltage-ampere characteristics at intermediate-frequencies under a transverse magnetic field (TMF). Niwa [8] researched the high-speed vacuum circuit breakers that are used in railway power systems. The relationship between the current waveform just before current zero and the interruption ability was investigated by varying the high frequency current source. In [9], Liu studied the characteristics of $270 \mathrm{~V}$ DC forcing interruptions. With a fixed average current rate $\mathrm{d} i / \mathrm{d} t$, the change law of the arc diameter was summarized. After high current, the strength of the dielectric recovery was decreased by the presence of metal vapors, residual plasmas, and metal droplets. As a result, this will cause breakdowns. Many researchers have discussed the droplet problem in early experiments using laser detecting technology. Shalev [10] found that the speed of the droplets is related to the melting temperature of the cathode, the instantaneous current value, and the size. Shmelev [11] described thermo-field electron emission and evaporation from the droplet surface and correspondent plasma creation. The droplet heating is self-consistently modeled, taking into account the influence of the plasma generated during the process. $\mathrm{Li}$ [12] observed that the ejection of molten droplet is along the tangent surface of electrode with a small divergent angle. The spatial varied droplet ejection causes a decrease in both flashover electric field and surface resistance. In $[13,14]$, researchers found that droplets and particles were emitted from the arc column between the $\mathrm{Cu}$ and $\mathrm{CuCr} 30 \mathrm{AMF}$ contacts with a rotating anode melting pool under high current. Jiang [15] found more macroscopic metal droplets can be seen in the intermediate frequency arc column between $\mathrm{CuCr} 50$ contacts. Mesyats $[16,17]$ theoretically studied the dynamics of molten metal during crater formation in the cathode spot of vacuum arc discharge. An analytic model of liquid-metal splashing that includes two stages is proposed.

In this paper, the interruption process of intermediate-frequency vacuum arcs is investigated through several experiments. Specifically, we will focus on arc reignition and droplet movement. With an increasing current value or frequency, both the peak value and the rise rate of the intermediate-frequency vacuum arc voltage increase. The interruption ability of the AMF vacuum circuit breaker decreases as the frequency increases for the rise rate of the voltage $\mathrm{d} u / \mathrm{d} t$ increases. In the range from $360 \mathrm{~Hz}$ to $850 \mathrm{~Hz}$, there is an approximate linear relationship between the limit interruption current value and the square of reciprocal of frequency. When the intermediate-frequency vacuum arc reignites, macroscopic metal droplets can be seen in the arc column between the CuCr50 contacts. The metal droplets and particles are the source of the plasmas and metal vapors related to reignition after the arc extinction.

\section{Experimental Setup}

The intermediate-frequency vacuum arc experimental setup is shown in Figure 1. The oscillating circuit, which includes the capacitor $\mathrm{C}_{1}$, inductance $\mathrm{L}_{1}$, bidirectional triode thyristor $\mathrm{VT}_{1}$, vacuum interrupter $\mathrm{VI}$, and shunt resistor $\mathrm{R}_{2}$, is utilized to generate the intermediate-frequency current. The arc holding branch, which consists of capacitor $\mathrm{C}_{2}$, power diode $\mathrm{VD}_{1}$, resistor $\mathrm{R}_{1}$, thyristor $\mathrm{VT}_{2}$, is used to generate the approximate direct current arc until the intermediate-frequency current is injected. The frequency regulation branch, which includes resistor $R_{0}$ and capacitor $C_{0}$, is used to adjust the rise rate of the recovery voltage between the contacts. The sequence of experimental operations is as follows. When capacitor $C_{1}$ and $C_{2}$ is charged to the rated voltage, the $\mathrm{VT}_{2}$ is first triggered as VI is closed, which causes the arc holding branch to begin to operate. After the VI contacts open, the approximate direct current arc is generated by the large time constant $\left(\tau=\mathrm{R}_{1} \times \mathrm{C}_{2}\right)$. The $\mathrm{VT}_{1}$ is triggered to inject intermediate-frequency current while the contacts are fully open. The $\mathrm{VT}_{2}$ is switched off for the negative voltage, because the charging voltage of $C_{1}$ is higher than that for $C_{2}$. The trigger signal of $\mathrm{VT}_{1}$ will extend to the end of the experiment. In this paper, we will adjust the values of $\mathrm{C}_{1}$ and $\mathrm{L}_{1}$ to vary the intermediate-frequency from $360 \mathrm{~Hz}$ to $850 \mathrm{~Hz}$. In the experiment, the absolute maximum value of the voltage probe is $2000 \mathrm{~V}$, and the maximum recovery voltage of the vacuum arc is approximately $500 \mathrm{~V}$. In order to avoid additional voltage, the voltage probe is placed between the anode contact and cathode contact outside the chamber, however as close as possible, as points $a$ and $b$ shown in Figure 1. We have also measured the intermediate frequency voltage when 
contacts are closed. The voltage peak value is less than $2 \mathrm{~V}$ when current is $20 \mathrm{kA}$, so the additional impedance is less than $0.1 \mathrm{~m} \Omega$. The shunt resistor $R_{2}$ with value of $0.6 \mathrm{~m} \Omega$ is used to measure the current. The voltage and current waveforms were recorded by a DL750 recorder (YOKOGAWA). The images of the arc were taken by a Phantom v7.3 digital high-speed camera. The frame rate was 35,087 frames/s, and the resolution of the arc images was $320 \times 240$. A commercial AMF vacuum circuit breaker without shield was used in the experiment. The air pressure inside the VI was below $5 \times 10^{-4} \mathrm{~Pa}$ and the number of coil turns was $1 / 4$. The diameter of the contacts was $41 \mathrm{~mm}$ and the contacts material was $\mathrm{CuCr} 50$ alloy. In the experiment, the gap between the contacts was $3 \mathrm{~mm}$.

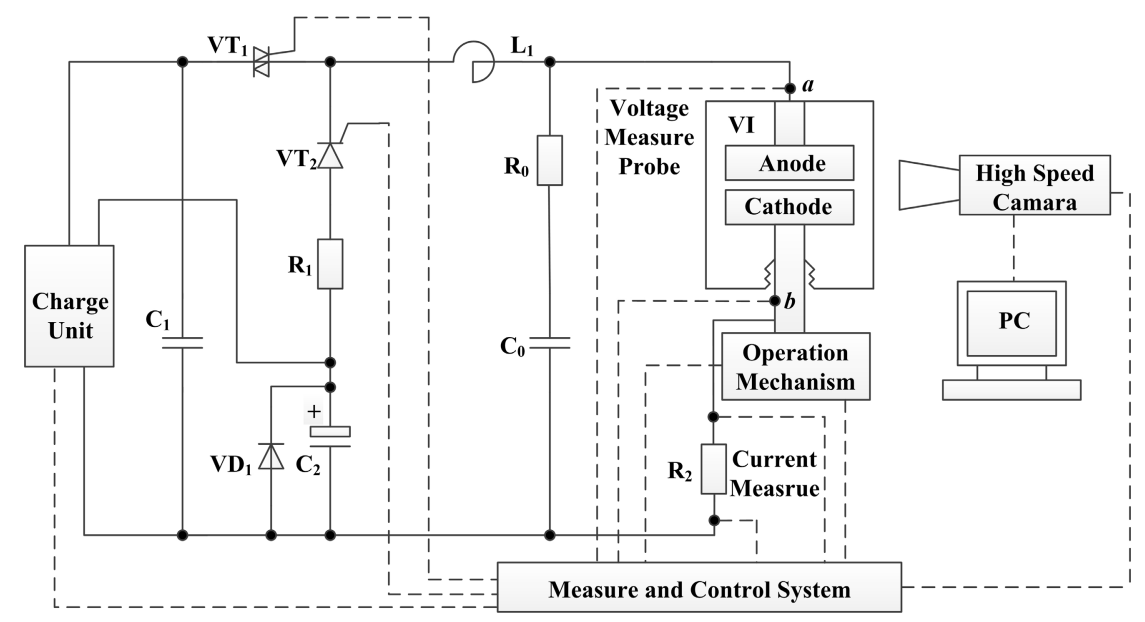

Figure 1. Schematic diagram of the experimental system.

\section{Results and Discussion}

\subsection{Intermediate-Frequency Vacuum Arc Voltage}

Figure 2 shows the vacuum arc current and voltage for different intermediate-frequencies and currents. According to the experiment data, it is found that an increase in vacuum arc voltage is related to frequency and current. Due to the thermal inertia of plasma, the ionization is inadequate. As a result, the arc resistivity should basically remain unchanged when the current is increasing, and in intermediate-frequency vacuum current, we have found that the arc path curves when the arc is burning at the lateral of contacts, which is equivalent to the length of arc column is lengthened. It can be seen that the arc resistance increases, which causes the rise of arc voltage [15]. As shown in the figure, as the frequency increases, the peak value of the voltage increases and the time of the peak value occurs earlier. If we consider the beginning of the current as the zero time, when the current peak value is $10 \mathrm{kA}$, the voltage peak increases from $36 \mathrm{~V}$ at $360 \mathrm{~Hz}$ to $44 \mathrm{~V}$ at $850 \mathrm{~Hz}$, and the time of appearance of the voltage peak is at $270.0 \mu \mathrm{s}$ at $360 \mathrm{~Hz}$ compared to $137.6 \mu \mathrm{s}$ at $850 \mathrm{~Hz}$. When the current peak value was $12.5 \mathrm{kA}$, the voltage peak increased from $50 \mathrm{~V}$ at $360 \mathrm{~Hz}$ to $58.7 \mathrm{~V}$ at $780 \mathrm{~Hz}$, and the time of appearance of the voltage peak was at $248.2 \mu \mathrm{s}$ at $360 \mathrm{~Hz}$ compared to $199.6 \mu \mathrm{s}$ at $780 \mathrm{~Hz}$. The specific data is shown in Table 1 . The rise rate of the voltage $\mathrm{d} u / \mathrm{d} t$ increases with the increase of frequency due to the increase in the voltage peak, and the time of the voltage peak appears earlier. After the peak, the voltage value decreases quickly and the rate is positively correlated to the frequency. There are no obvious differences before the voltage zero time.

The curves of the arc voltage peak and intermediate-frequency current period are displayed in Figure 3, which shows the current peak value of $10 \mathrm{kA}, 12.5 \mathrm{kA}$, and $14.4 \mathrm{kA}$. As shown, for the same frequency, larger voltage peak values are related to larger current peak values, while with the same current peak, the voltage peak value gets larger if the frequency increases. At the same time, it can be seen that the relationship between voltage peak value and period is approximately linear. The gradients of the three curves are very similar. 

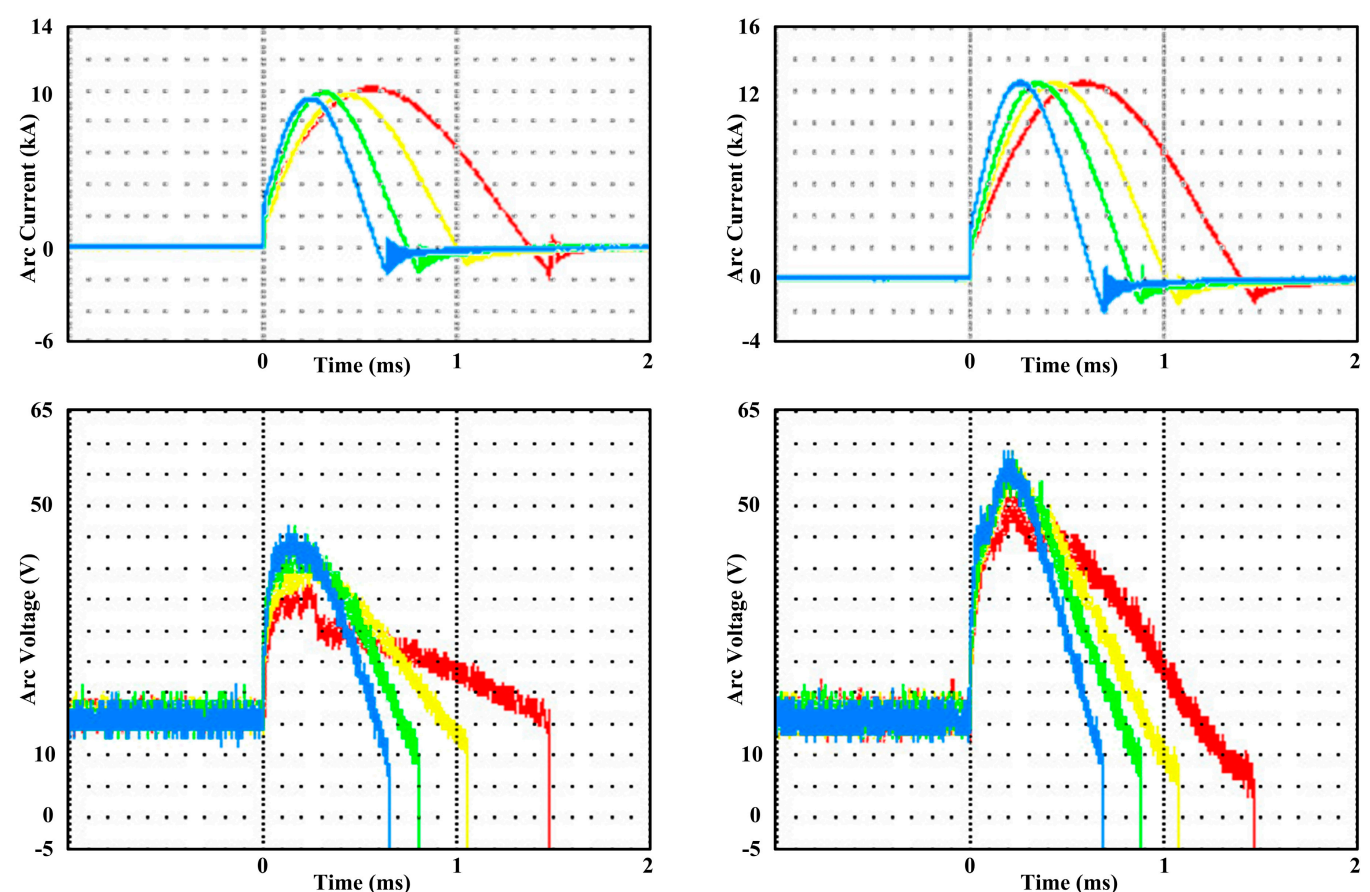

(a) $I_{\text {peak }}=10 \mathrm{kA}$

(b) $I_{\text {peak }}=12.5 \mathrm{kA}$

Figure 2. Vacuum arc current and voltage in different frequency $\left(I_{\text {peak }}=10 \mathrm{kA}\right.$ and $\left.12.5 \mathrm{kA}\right)$.

Table 1. Peak value and time of arc voltage at different frequencies ( $I_{\text {peak }}=10 \mathrm{kA}$ and $\left.12.5 \mathrm{kA}\right)$.

\begin{tabular}{ccccc}
\hline $\boldsymbol{I}_{\text {peak }}(\mathbf{k A})$ & $f(\mathbf{H z})$ & $\boldsymbol{T}=\mathbf{1} / \boldsymbol{f}(\mathbf{m s})$ & $\boldsymbol{U}_{\text {peak }}(\mathbf{V})$ & $U_{\text {peak }}$ Time $(\boldsymbol{\mu s})$ \\
\hline 10 & 360 & 2.78 & 36.0 & 270.0 \\
& 500 & 2.00 & 41.3 & 262.0 \\
& 680 & 1.47 & 43.3 & 172.6 \\
\multirow{3}{*}{12.5} & 800 & 1.18 & 44.0 & 137.6 \\
& 360 & 2.78 & 50.0 & 248.2 \\
& 500 & 2.00 & 56.0 & 218.6 \\
& 600 & 1.67 & 57.3 & 213.0 \\
& 780 & 1.28 & 58.7 & 199.6 \\
\hline
\end{tabular}
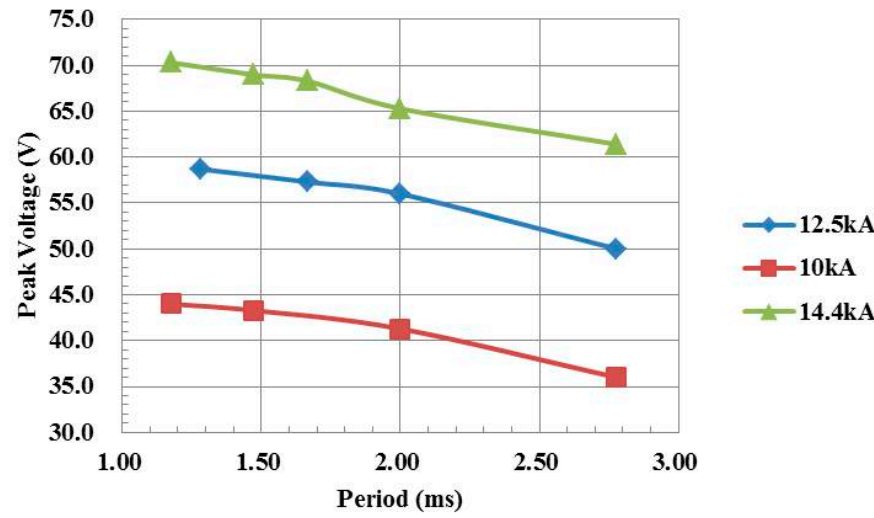

Figure 3. Peak value of arc voltage in different frequency.

If we consider the current frequency $f$ to be independent variables, and the voltage peak $U_{\text {peak }}$ to be a dependent variable, the following function can be obtained:

$$
U_{\text {peak }}=U_{\mathrm{I}}-\frac{k_{f}}{f}
$$


Based on the experimental data, $k_{f}$ and $U_{\mathrm{I}}$ can be calculated by fitting, and the results are shown in Table 2.

Table 2. $k_{f}$ and $U_{\mathrm{I}}$ calculated by fitting.

\begin{tabular}{ccc}
\hline $\boldsymbol{I}_{\text {peak }}(\mathbf{k A})$ & $\boldsymbol{k}_{f}(\mathrm{~V} / \mathbf{m s})$ & $\boldsymbol{U}_{\mathbf{I}}(\mathrm{V})$ \\
\hline 10 & 5.0589 & 50.54 \\
12.5 & 5.9162 & 66.93 \\
14.4 & 5.7587 & 77.33 \\
\hline
\end{tabular}

From these results, $k_{f}$ is almost constant while $U_{\mathrm{I}}$ changes a lot. This can be explained as follows: in a linear relationship, $k_{f}$, which is the coefficient of $f$, should be independent of $f$. Only one vacuum circuit breaker is used in the experiment, so $k_{f}$ must be related to the structural parameters, such as the gap distance and contact diameter. $U_{\mathrm{I}}$ shows the current effects on the arc voltage. According to power frequency research, the vacuum arc voltage increases as the current increases. Furthermore, a similar conclusion can be drawn in the $400 \mathrm{~Hz}$ experiment [3].

After fitting $U_{\mathrm{I}}$ and $I_{\text {peak }}$, the following equation can be obtained:

$$
U_{\mathrm{I}}=6.115 I_{\text {peak }}-10.314
$$

The direct proportional relationship between $U_{\mathrm{I}}$ and $I_{\text {peak }}$ is described in Equation (2), and the correlation coefficient is as high as 0.9975 . However, $U_{\mathrm{I}}$ should be positive if $I_{\text {peak }}$ is near zero. As a result, the equation must be modified:

$$
U_{\mathrm{I}}=0.2503 I_{\text {peak }}^{2}+26.215=k_{\mathrm{I}} \cdot I_{\text {peak }}^{2}+U_{\mathrm{C}}
$$

In Equation (3), $k_{\mathrm{I}}$ is the coefficient of the current peak, and $U_{\mathrm{C}}$ is the voltage constant. In summary, the relationship between the voltage peak, current peak, and period can be expressed as follows:

$$
U_{\text {peak }}=U_{\mathrm{I}}-\frac{k_{f}}{f}=k_{\mathrm{I}} \cdot I_{\text {peak }}^{2}-\frac{k_{f}}{f}+U_{\mathrm{C}}
$$

According to Equation (4), it is shown that vacuum arc voltage is related to frequency and current. Regardless of whether the current or frequency increases, the current rise rate $\mathrm{d} i / \mathrm{d} t$ will also increase. On the one hand, more electrons will be injected into the arc in a unit time, so more ions will appear near the anode. As a result, the arc voltage will quickly rise to a certain level in the same amount of time, which will produce enough ions and create an electric field to attract the electrons. On the other hand, if the axial magnetic field lags at the start of the current, the vacuum will lack magnetic restrictions. Consequently, the ions can spread quickly outside the contact, which causes a shortage of ions near the anode. Thus, the arc voltage must increase to a certain level fast enough to sustain the plasma balance. In addition, the higher the frequency, the more serious the shortage is. Electrons are emitted from the cathode. Since the characteristics of the plasma are quasi-neutral, the distance between electrons and ions will not be greater than the Debye length. In the micro-area, the electrons turn around the ions at high speed and ions move slower than electrons. As a result, there is a greater impact on ions than electrons by a lack of magnetic restriction. In the two situations, the voltage peak and the rise rate of the voltage $\mathrm{d} u / \mathrm{d} t$ will increase.

\subsection{Interruption Ability Related to the Frequency}

The limit interruption current values for different frequencies are listed in Table 3. As shown, the interruption ability decreases as the frequency increases. 
Table 3. Limit interruption current value for different frequencies.

\begin{tabular}{ccc}
\hline$f(\mathbf{H z})$ & $\boldsymbol{T}=\mathbf{1} / \boldsymbol{f}(\mathbf{m s})$ & $\boldsymbol{I}_{\text {peak }}(\mathbf{k A})$ \\
\hline 360 & 2.78 & 22.5 \\
500 & 2.00 & 16.5 \\
600 & 1.67 & 15.5 \\
680 & 1.47 & 15.0 \\
850 & 1.18 & 14.0 \\
\hline
\end{tabular}

The short interruption current is $50 \mathrm{kA} / 40 \mathrm{kA}$ for the experimental BD010 vacuum breaker, for the conditions of $380 \mathrm{~V} / 660 \mathrm{~V}$ at a power frequency of $50 \mathrm{~Hz} / 60 \mathrm{~Hz}$. However, according to these results, the interruption ability decreases significantly in the intermediate-frequency experiment. In the former power frequency vacuum arc investigation, Voshall [18] believed that the current interruption ability was in inverse proportion to the frequency.

Based on the foregoing, the interruption of the AMF vacuum circuit breaker decreases as the current frequency increases. In the range of $360 \mathrm{~Hz}$ to $850 \mathrm{~Hz}$, the relationship between the two variables can be simplified for convenience, as follows. If the square of the current is used as the horizontal ordinate and the limit current interruption peak as the vertical ordinate, an approximate linear curve can be drawn, as shown in Figure 4.

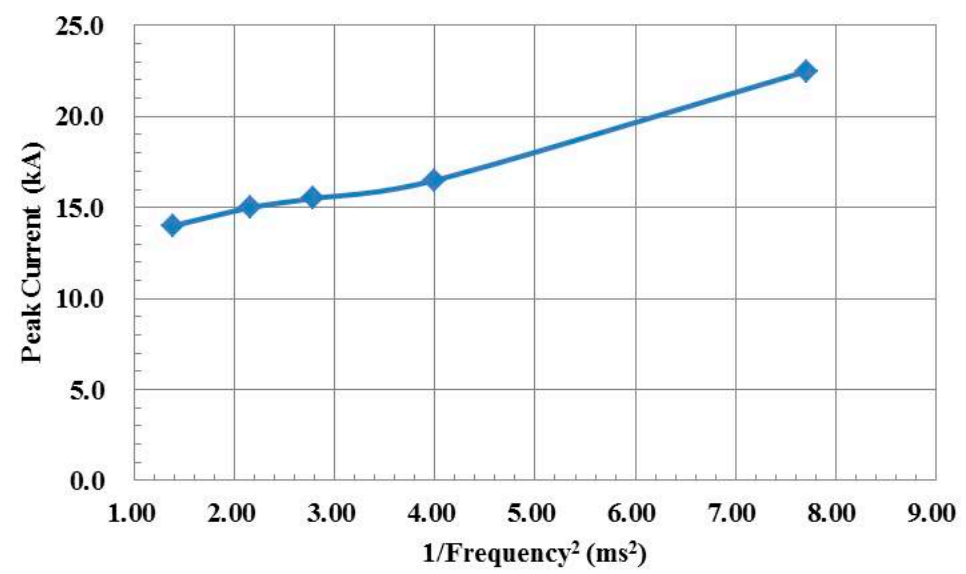

Figure 4. Relationship of limit interruption and frequency.

Using the least squares method, the relational expression is:

$$
I_{\text {peak-limit }}=\frac{a}{f^{2}}+b
$$

where $a=1.34 \mathrm{kA} / \mathrm{ms}^{2}$ and $b=11.86 \mathrm{kA}$. The main reason why the interruption limit decreases is that the rise rate of the voltage $\mathrm{d} u / \mathrm{d} t$ increases as the frequency increases.

When compared to the same current in power frequency, the arc time of the intermediatefrequency is shorter and the injected arc energy is lower. Consequently, the erosion of the contacts is weaker. Thus, it can be inferred that the possibility of severe anode activity is lower, which can be proven by the erosions of the electrodes, which reflects the thermal state of the electrodes, as shown in the $\mathrm{CuCr} 50$ electrode surface photos in Figure 5. Among which, in a successful interruption case, the upper contact is the anode and the lower contact is the cathode. While in the failed interruption case, the current is inverted after reignition, and the upper contact becomes the new cathode and the lower contact becomes the new anode. As a whole, the upper electrode operates longer as the anode. Compared to similar currents and contact materials in power frequency experiments [13], there are uniform and shallow melted marks on the electrode surface after intermediate-frequency experiments through macroscopic observation, and the erosion on the anode is clearer than on the 
cathode. However, serious erosions with large squares cannot be observed. From this, we can conclude that there are no obvious active anode spots or intense arc modes.

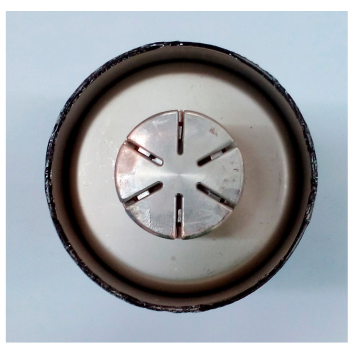

(a) The upper electrode

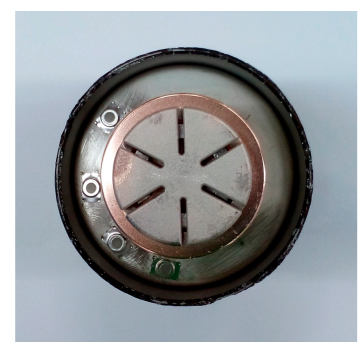

(b) The lower electrode

Figure 5. $\mathrm{CuCr} 50$ electrodes after several experiments.

\subsection{Droplet Emission and Arc Reignition}

When the interruption fails, there will be a process from arc extinction to arc reignition. Pictures in the second half are displayed in detail in Figure 6, with a current peak of $22.5 \mathrm{kA}$ and a frequency of $360 \mathrm{~Hz}$. In these photos, the upper contact is new cathode and the lower contact is new anode.

The droplets that are emitted from anode and cathode can be clearly seen. After arc extinction, the temperature is high, meanwhile the density of the residual plasmas and metal vapors are large inside the interrupter [19]. So, when new energy is injected after reignition, more and larger metal droplets will be emitted. Droplet emission from vacuum arc is well known and is due to the high pressure in arc spots. Mesyats [16] discussed the dynamics of molten metal during crater formation in the cathode spot of vacuum arc discharge and illustrated that the pressure of the cathode spot plasma causes the extrusion of molten metal from the hemispherical depression. However, in this paper, we are concerned with the movement process of droplet and arc column pressure, and even if droplets are not charged, it can be a source of metal vapors and plasmas that account for field emission and vacuum gap breakdown.

According to the xoy coordinate system, the selected measuring point A was marked with a red circle in Figure 6. In the reignition process at $500 \mathrm{~Hz}, 600 \mathrm{~Hz}$ and $680 \mathrm{~Hz}$, the same coordinate system and selected measuring points were used in each process. Considering the electrode diameter of $41 \mathrm{~mm}$ as the reference object, the coordinates of every time are recorded. Then, the moving trace of droplets can be observed, as shown in Figure 7, in which the arrow shows the direction of movement.

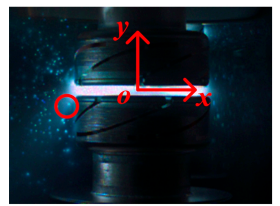

$t_{1}=29 \mu \mathrm{s}$

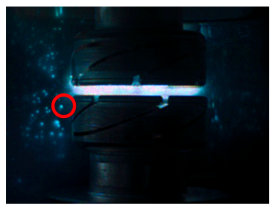

$t_{6}=174 \mu \mathrm{S}$

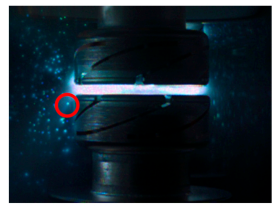

$t_{2}=58 \mu \mathrm{s}$

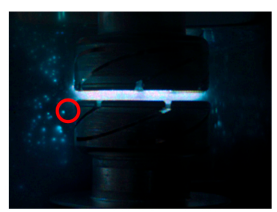

$t_{7}=203 \mu \mathrm{s}$

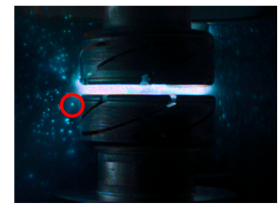

$t_{3}=87 \mu \mathrm{s}$

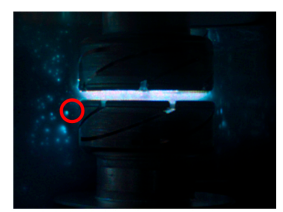

$t_{8}=232 \mu \mathrm{s}$

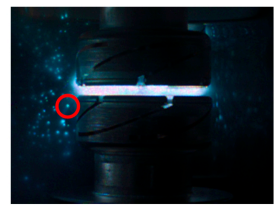

$t_{4}=116 \mu \mathrm{s}$

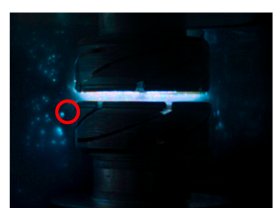

$t_{9}=261 \mu \mathrm{s}$

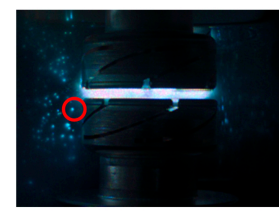

$t_{5}=145 \mu \mathrm{s}$

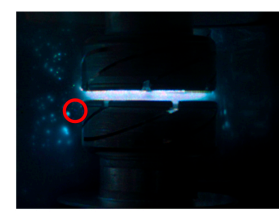

$t_{10}=290 \mu \mathrm{s}$

Figure 6. Droplet emission and movement during arc reignition $(360 \mathrm{~Hz})$. 


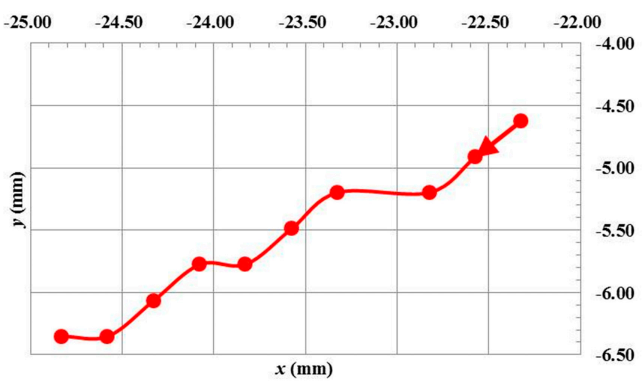

(a) $f=360 \mathrm{~Hz}$

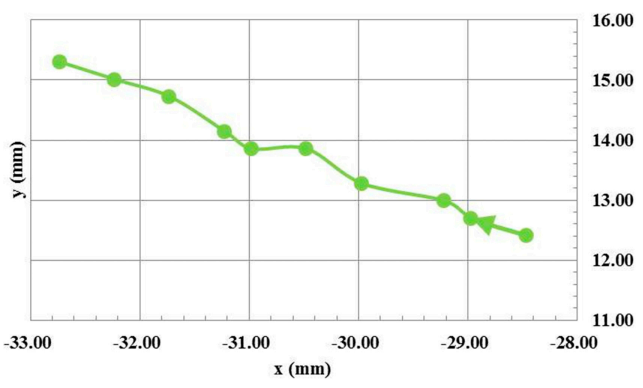

(c) $f=600 \mathrm{~Hz}$

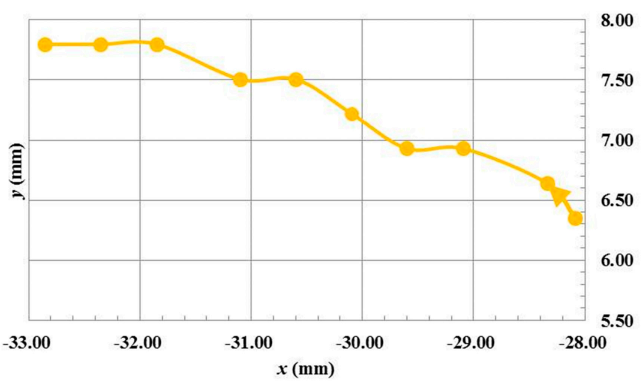

(b) $f=500 \mathrm{~Hz}$

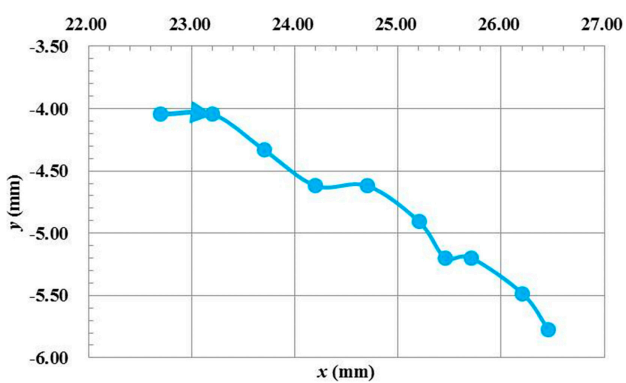

(d) $f=680 \mathrm{~Hz}$

Figure 7. Moving trace of droplets at different frequencies.

Based on the moving trace in two dimensions, the movement is not very affected by the frequency. After being emitted from the contact, the droplet moves toward the shield with an almost constant emitting $\beta$, which refers to the horizontal direction and can be calculated from the coordinates. The displacement-time curves for each droplet are shown in Figure 8a. It can be seen that there is an acceleration process $A$ and an even speed process B, as indicated by the dotted line in every curve. The acceleration process $\mathrm{A}$ is expressed in Figure $8 \mathrm{~b}$ and the uniform motion process B in Figure 8c, and the equations for displacement-time of the movement are obtained using quadratic fitting and linear fitting methods.

The above process can be explained as follows: there are electrons, ions, metal vapor, and droplets in the arc area, so the pressure in the center is larger than that near the shield, which can cause the droplets to accelerate [19]. In the former stage, the droplets start to leave the contacts and the arc gap where there is a large pressure, so it is an accelerating process. Then, in the later stages, the droplets have already left the gap where the pressure is small. Thus, it can be considered to be a uniform motion process. Based on the data, both the acceleration $a$ in the accelerating process and the average velocity $v_{\text {avg }}$ in the entire process can be obtained, as listed in Table 4.

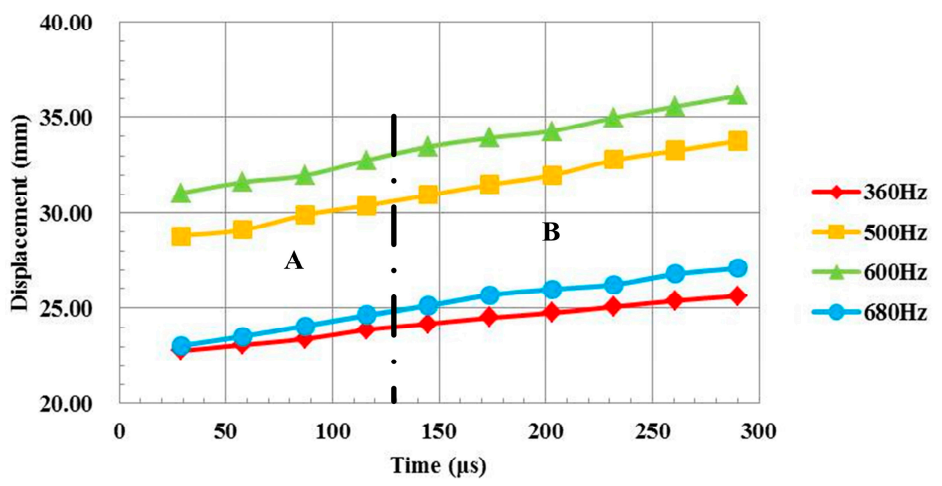

(a) the whole movement process

Figure 8. Cont. 


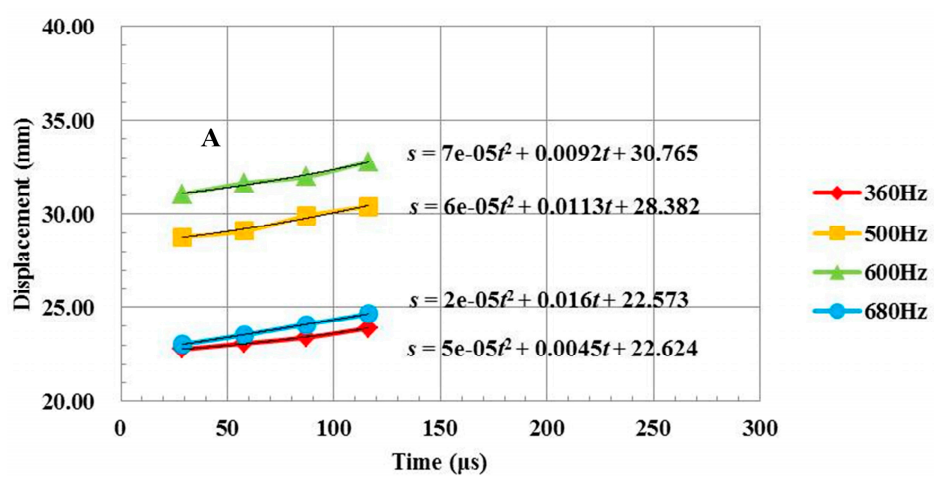

(b) the acceleration process

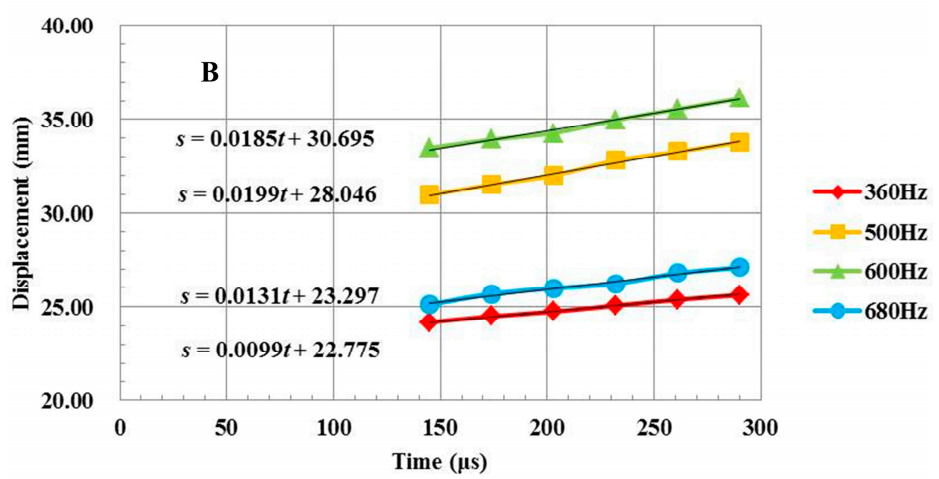

(c) the uniform motion process

Figure 8. Curves of displacement-time for droplets at different frequencies.

Table 4. Parameters of droplet movement.

\begin{tabular}{cccc}
\hline$f(\mathbf{H z})$ & $\boldsymbol{\beta}\left({ }^{\circ}\right)$ & $\boldsymbol{v}_{\text {avg }}(\mathrm{m} / \mathbf{s})$ & $\boldsymbol{a}\left(\mathrm{m} / \mathbf{s}^{\mathbf{2}}\right)$ \\
\hline 360 & 13.24 & 10.86 & $10 \times 10^{4}$ \\
500 & 13.40 & 19.04 & $12 \times 10^{4}$ \\
600 & 24.30 & 19.44 & $14 \times 10^{4}$ \\
680 & 10.99 & 15.43 & $4 \times 10^{4}$ \\
\hline
\end{tabular}

Due to the calculation results, the order of magnitude for the acceleration is up to $10^{4} \mathrm{~m} / \mathrm{s}^{2}$, so the droplets must be influenced by an outside force. If we consider the emitted metal droplets to be spherules and refer to the motion direction as $\beta$, we can establish the pressure $P$ as shown in Figure 9a.

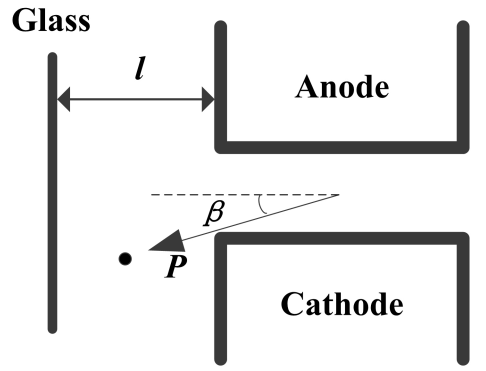

(a) Schematic diagram for droplet and pressure in vacuum chamber

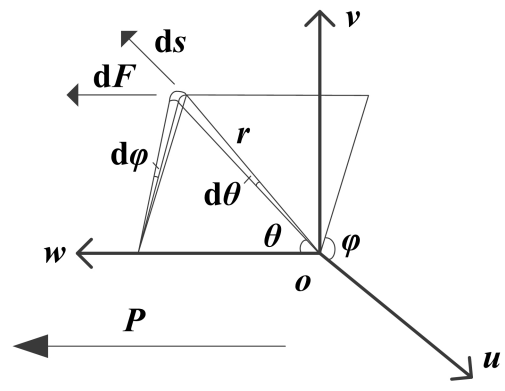

(b) Spherical coordinate system inside a droplet

Figure 9. Movement and pressure of metal droplet in vacuum chamber. 
Considering the radius of the metal droplet as $r$, a spherule coordinate system is established inside the droplet and the direction of pressure is referred to as $+w$. As shown in Figure 9, the force $\mathrm{d} F$ on the $\mathrm{d} s$ is:

$$
\mathrm{d} F=P \cdot \mathrm{d} s \cdot \cos \theta
$$

The cell area ds in the spherule coordinate system is:

$$
\mathrm{d} s=r \cdot \sin \theta \cdot \mathrm{d} \varphi \cdot r \cdot \mathrm{d} \theta
$$

If the particulate is too small, the pressure gradient in the $w$ direction can be considered constant in $[-r, r]$. If the outside force is taken into account, the pressure is $P_{0}$ where $w=0$, and the pressure $P$ at any angle can be expressed as:

$$
P=P_{0}+\frac{\partial P}{\partial w} \cdot w=P_{0}+\frac{\partial P}{\partial w} \cdot r \cdot \cos \theta
$$

By substituting Equations (7) and (8) into Equation (6), the following equation is obtained:

$$
\mathrm{d} F=r^{2} \sin \theta \cos \theta\left(P_{0}+\frac{\partial P}{\partial w} R \cos \theta\right) \mathrm{d} \varphi \mathrm{d} \theta
$$

The force of the whole spherule can be obtained by integration:

$$
\begin{aligned}
& F=\int_{0}^{2 \pi} \mathrm{d} \varphi \int_{0}^{\pi} r^{2} \sin \theta \cos \theta\left(P_{0}+\frac{\partial P}{\partial w} R \cos \theta\right) \mathrm{d} \theta \\
& =\frac{4}{3} \pi r^{3} \frac{\partial P}{\partial w}
\end{aligned}
$$

Referring to Newton's second law without gravity, the outside force of the droplet is:

$$
F=m a=\frac{4}{3} \pi r^{3} \rho a
$$

where $\rho$ is the density of the metal droplet.

By analyzing the deposited metal inside the glass shield using a scanning electron microscope (SEM), the components shown in Table 5 were observed.

Table 5. Solidification component inside shield detected by SEM.

\begin{tabular}{ccccc}
\hline Element & $\mathbf{C u}$ & $\mathbf{C r}$ & $\mathbf{C}$ & $\mathbf{O}$ \\
\hline weight percentage & $54.46 \%$ & $32.89 \%$ & $7.16 \%$ & $5.48 \%$ \\
atomic percentage & $24.56 \%$ & $26.04 \%$ & $24.56 \%$ & $14.11 \%$ \\
\hline
\end{tabular}

$\mathrm{C}$ and $\mathrm{O}$ are supposed to be foreign substance for less content. According to the data shown in Table 5 and the density of $\mathrm{Cu}$ and $\mathrm{Cr}$, the density of the emitted alloy was calculated to be approximately $\rho \approx 7.9 \times 10^{3} \mathrm{~kg} / \mathrm{m}^{3}$.

If the acceleration $a$ is $10^{4} \mathrm{~m} / \mathrm{s}^{2}$, then the pressure gradient can be obtained based on the above results:

$$
\frac{\partial P}{\partial w}=\rho a=8.2 \times 10^{3} \times 10^{4}=7.9 \times 10^{7} \mathrm{pa} / \mathrm{m}
$$

If the pressure gradient is considered to be constant along the direction of the metal droplet, and the acceleration distance $l_{\mathrm{a}}$ is $1.5 \mathrm{~mm}$ in the experimental interrupter shown in Figures 6-8, then the pressure from the contact edge to the shield is:

$$
P=\frac{\partial P}{\partial w} \cdot l_{a}=7.9 \times 10^{7} \times 1.5 \times 10^{-3}=0.118 \mathrm{Mpa}
$$


In reality, there are inaccuracies in the above calculation because the pressure gradient is not constant everywhere. However, from the order of magnitude in the result, in the vacuum chamber, there is a large pressure from the center of the contact to the edge, which causes the electrons, ions, and metal droplets to accelerate and spread. At high current levels, if the density of the plasmas and metal vapors, and the number of metal droplets reaches a certain level, the arc may break down, which will cause the interruption to fail.

On the other hand, the half wave time of current at $360 \mathrm{~Hz}$ is $1.4 \mathrm{~ms}$. The shortest distance $l$ from the contact to the shield is $30 \mathrm{~mm}$ in the experimental interrupter. Based on an overall consideration of the former study and Table 4, we can make the following hypothesis: the emitting angle of the metal droplet $\beta$ is $20^{\circ}$, and the average velocity $v_{\text {avg }}$ is $15 \mathrm{~m} / \mathrm{s}$. The moving time $\mathrm{t}$ from the contact to the glass shield can be calculated by Equation (14):

$$
t=\frac{l}{\cos \beta \cdot v_{\text {avg }}}=\frac{0.03}{\cos 20^{\circ} \cdot 15}=2.2 \mathrm{~ms}
$$

That is, at current zero, the droplet will disappear after a period which is approximately equal to the half wave time of the intermediate-frequency current. Based on this, the metal droplets and particles are the source of the plasma in the space after the arc is extinguished, which may cause the arc to reignite.

\section{Conclusions}

With an increasing current value or frequency, both the peak value and the rise rate of the intermediate-frequency vacuum arc voltage increase. On the one hand, as $\mathrm{d} i / \mathrm{d} t$ increases, more electrons will be injected into the arc in a unit time. On the other hand, the axial magnetic field becomes much more inhomogeneous as the frequency increases, which causes the magnetic restriction to be weaker at the beginning of current. As a result, the ions can spread quickly outside the contact. In these two cases, there will be a shortage of ions near the anode. Therefore, the arc voltage must quickly rise to a certain level in order to produce enough ions and sustain the balance of the plasma.

The interruption ability of the AMF vacuum circuit breaker decreases as the frequency increases for the rise rate of the voltage $\mathrm{d} u / \mathrm{d} t$ increases. In the range from $360 \mathrm{~Hz}$ to $850 \mathrm{~Hz}$, there is an approximate linear relationship between the limit interruption current value and the square of reciprocal of frequency. Compared to the power frequency under similar conditions, the arc time of the intermediate-frequency is shorter and the injected arc energy is less, which causes the erosion of the contacts to be weaker. There are uniform and shallow melted marks on the electrode surface after experiment. However, serious erosion with large squares cannot be observed. From this, it can be concluded that there were no obvious active anode spots or intense arc modes.

When the intermediate-frequency vacuum arc reignites, macroscopic metal droplets can be seen in the arc column between the $\mathrm{CuCr} 50$ contacts. The velocity of droplet emission was determined by calculation to be approximately $10 \mathrm{~m} / \mathrm{s}$ to $20 \mathrm{~m} / \mathrm{s}$. In the vacuum chamber, there was huge pressure from the arc area to the edge, which forced electrons, ions, and droplets to spread outside. At the current zero time, the droplets will be solidified at the inner shield after a period equal to the half wave time. Based on this, the metal droplets and particles are the source of the plasmas and metal vapors related to reignition after the arc extinction. If the density of plasmas and metal vapors and the number of metal droplets reaches a certain level, the arc may break down, which will cause the interruption to fail.

Acknowledgments: This study was co-supported by the National Natural Science Foundation of China (No. 51377007), the Specialized Research Fund for the Doctoral Program of Higher Education (No. 20131102130006), and the Fundamental Research Funds for the Central Universities. We would like to thank Editage (www.editage. cn) for English language editing.

Author Contributions: Yuan Jiang conceived of the condition assessment model and wrote most parts of the manuscript. Jianwen Wu, Mingxuan Chen and Wenlei Huo analyzed the data and checked the whole paper. 
Conflicts of Interest: The authors declare no conflict of interest.

\section{References}

1. Chen, J.; Zhang, X.; Wen, C. Harmonics attenuation and power factor correction of a more electric aircraft power grid using active power filter. IEEE Trans. Ind. Electron. 2016, 63, 7310-7319. [CrossRef]

2. Gao, F.; Bzhko, S.; Asher, G.; Wheeler, P.; Patel, C. An improved voltage compensation approach in a droop-controlled dc power system for the more electric aircraft. IEEE Trans. Power Electron. 2016, 31, 7369-7383. [CrossRef]

3. Wang, J.; Wu, J.; Zhu, L. Properties of intermediate-frequency vacuum arc under axial magnetic field. IEEE Trans. Plasma Sci. 2009, 37, 1477-1483. [CrossRef]

4. Wang, J.; Wu, J.; Zhu, L. Arc behavior of intermediate-frequency vacuum arc on axial magnetic field contacts. IEEE Trans. Plasma Sci. 2011, 39, 1336-1343.

5. Zhu, L.; Wu, J.; Zhang, X. Arc movement of intermediate-frequency vacuum arc on TMF contacts. IEEE Trans. Power Deliv. 2013, 28, 2014-2021.

6. Zhu, L.; Wu, J.; Liu, B.; Feng, Y. The dynamic volt-ampere characteristics of a vacuum arc at intermediate-frequency under a transverse magnetic field. Plasma Sci. Technol. 2013, 15, 30-36. [CrossRef]

7. Zhu, L.; Wu, J.; Jiang, Y. Motion and splitting of vacuum arc column in transverse magnetic field contacts at intermediate-frequency. Plasma Sci. Technol. 2014, 16, 454-459. [CrossRef]

8. Niwa, Y.; Yokokura, K.; Matsuzaki, J. Fundamental investigation and application of high-speed vcb for dc power system of railway. In Proceedings of the 24th International Symposium Discharges and Electrical Insulation in Vacuum (ISDEIV), Braunschweig, Germany, 30 August-3 September 2010; pp. 125-128.

9. Liu, B.; Wu, J.; Xin, C. Study on dynamic characteristic in force interrupted dc vacuum arc. IEEE Trans. Plasma Sci. 2014, 42, 2382-2383.

10. Shalev, S.; Boxman, R.L.; Goldsmith, S. Macroparticle dynamics during multi-cathode-spot vacuum arcs. IEEE Trans. Plasma Sci. 1986, PS-14, 59-62. [CrossRef]

11. Shmelev, D.L.; Uimanov, I.V. Kinetic modeling of heating of metal microdroplet by surrounding plasma. IEEE Trans. Plasma Sci. 2013, 41, 1974-1978. [CrossRef]

12. Li, X.; Liu, X.; Zeng, F.; Guo, X.; Zhang, Q. Ejection of electrode molten droplet and its effect on the degradation of insulator in gas spark switches. IEEE Trans. Plasma Sci. 2015, 43, 1049-1057.

13. Yang, D.; Wang, L.; Jia, S.; Wang, L.; Shi, Z.; Li, Y. Experimental investigation of anode activities in high-current vacuum arcs. IEEE Trans. Plasma Sci. 2010, 38, 206-213. [CrossRef]

14. Wang, L.; Wang, L.; Jia, S.; Shi, Z.; Yang, D.; Liu, Y. Experimental study of anode activities in high current vacuum arc subjected to axial magnetic fields under different conditions. IEEE Trans. Plasma Sci. 2010, 38, 1682-1691. [CrossRef]

15. Jiang, Y.; Wu, J. Interruption phenomenon in intermediate-frequency vacuum arc. Plasma Sci. Technol. 2016, 18, 311-318. [CrossRef]

16. Mesyats, G.A.; Zubarev, N.M. The Rayleigh-Plateau instability and jet formation during the extrusion of liquid metal from craters in a vacuum arc cathode spot. J. Appl. Phys. 2015, 117, 1-5. [CrossRef]

17. Gashkov, M.A.; Zubarev, N.M.; Zubareva, O.V.; Mesyats, G.A.; Uimanov, I.V. Model of liquid-metal splashing in the cathode spot of a vacuum arc discharge. J. Exp. Theor. Phys. 2016, 122, 776-786. [CrossRef]

18. Voshall, R.E. Current interruption ability of vacuum switche. IEEE Trans. Power Appar. Syst. 1972, PAS-91, 1219-1224. [CrossRef]

19. Hartmann, W.; Lawall, A.; Renz, R.; Romheld, M.; Wenzel, N.; Wietzorek, W. Cathode spot dynamics and arc structure in a dense axial magnetic-field-stabilized vacuum arc. IEEE Trans. Plasma Sci. 2011, 39, 1324-1329. [CrossRef]

(C) 2017 by the authors. Licensee MDPI, Basel, Switzerland. This article is an open access article distributed under the terms and conditions of the Creative Commons Attribution (CC BY) license (http:/ / creativecommons.org/licenses/by/4.0/). 